\title{
A Team-effectiveness Inventory for Guided Reflection and Feedback
}

\section{Ms. Patricia Kristine Sheridan, University of Toronto}

Patricia Kristine Sheridan is a PhD Candidate with the Institute for Leadership Education in Engineering at the University of Toronto. She holds a BASc and MASc in Mechanical Engineering from the University of Toronto. She is a member of the teaching team and a course developer for the Praxis cornerstone design courses.

Miss Lobna El Gammal , Institute For Leadership Education in Engineering at the University of Toronto

Lobna El Gammal is currently completing her third year of chemical engineering studies at the University of Toronto. She is pursuing a certificate of global engineering and working towards an optional fourth-year thesis with the Institute for Leadership Education in Engineering (ILead) at the University of Toronto.

Previously, she worked as a pilot analyst summer research student, with both ILead and Patricia Sheridan, to develop a team effectiveness inventory for guided reflection and feedback. Lobna was responsible for performing quantitative and qualitative analysis of the pilot project findings and for modifying the proposed inventory based on analysis.

Lobna is passionate about engineering education and plans to pursue a career path in the field.

\section{Jennie Phillips MA, University of Toronto}

Jennie Phillips, MA Ed. Tech, is a specialist in instructional design from Concordia University. She has experience working in the government sector with the Privy Council Office / Prime Ministers Office and the Department of Foreign Affairs developing and delivering emergency management training programs, and private / non-profit sector as a social entrepreneur (through her company ellips design + consulting) overseas in Swaziland and India providing Information Communications \& Technology (ICT) and Training consulting. At present, Jennie is pursuing a $\mathrm{PhD}$ at the University of Toronto at the Ontario Institute for Studies in Education (OISE) and Munk School of Global Affairs. Her research interests include just-in-time training, citizen-driven online response to crisis, collaboration online in crises, strategy identification (policy, awareness, training and innovation), and integration of online communities into official emergency response channels. She holds 6 years experience working in Emergency Management and over 9 years working in Education and ICT.

\section{Dr. Greg Evans, University of Toronto}

Professor Dept. of Chemical Engineering and Applied Chemistry Director Southern Ontario Centre for Atmospheric Aerosol Research Associate Director Institute of Leadership Education in Engineering

Prof Evans has been recognised as a researcher, educator, and for his contributions to students experience. His research focuses on the sources and chemistry of atmospheric aerosol particles, and their impacts on air quality, public health, and climate. As the Associate Director of the Institute of Leadership Education in Engineering, he is also working to enhance engineering education and increase the positive impact of engineers on society through the instruction of leadership competencies.

\section{Dr. Doug Reeve P.Eng., University of Toronto}




\section{A Team-effectiveness Inventory for Guided Reflection and Feedback}

This paper presents the development and refinement of the Team-effectiveness Inventory (TEI) used to facilitate student self- and peer-assessments of individual team-effectiveness in teambased project courses. The objective of the TEI is to create a common language by which guided reflection and feedback can be provided based on visible behaviour competencies as a means to engage students in learning about and improving their individual team-effectiveness. An initial version of the TEI was developed with three aspects (organizational, relational and communication) and 27 competencies. This TEI was studied through responses collected in a first year engineering design class of 250 students in Winter 2012. Correlation analysis was applied to student assessments and combined with the qualitative analyses of survey and focus group feedback from the teaching assistants and students to develop an understanding of how students perceive and use the inventory. Based on this analysis, the 27 competencies were reduced to 18. Student perceptions of the inventory as well as details of the modifications made to the TEI are presented herein.

\section{Introduction}

Team-based projects have become a common teaching practice in engineering courses as a means to simulate real-world environments. In these courses, students are often instructed on the technical aspects of the project material explicitly, but are expected to learn how to function effectively as a team implicitly. ${ }^{1}$ Team-based projects offer students rich learning opportunities to absorb course material while simultaneously developing important teamwork skills - provided student learning in both areas is addressed. Students can gain conceptual knowledge relating to team development and function through lectures, however, personalized feedback and reflection are also needed for them to learn from their actual teamwork experiences. Given the focus of current engineering curricula on developing technical competencies, students are implicitly taught to undervalue the need for leadership and interpersonal skills, such as effective teamwork, even though these are desired by the profession. ${ }^{1}$ Thus, a web-based tool is being developed at the University of Toronto in response to the required graduate attributes to create an explicit method of facilitating students to learn about and engage in improving their individual teameffectiveness through team-based projects in design courses.

The effectiveness of a student in a team, as approached in this work, is the ability of the student to contribute to team performance in a manner that: i) focuses on putting the performance needs of the team before their own, ii) takes an open and cooperative approach to the work, and iii) values and leverages the abilities and contributions of all team members. To facilitate developing these ideal behaviours in students, this approach aims to develop individual team-effectiveness competencies that are necessary to create a high-performance team. Developing these competencies in the individual instead of the team as a whole is necessary as students change project teams across courses and need to be able to use these skills in their work after graduation; the competencies developed by these students need to be transferable across different project teams. These competencies can be seen as the individual building blocks of team-effectiveness; the more competent a student is, the stronger their building blocks, and the more students with greater individual effectiveness, the stronger the structure their entire team can build. Similar 
approaches to developing individual behaviour competencies around teamwork in engineering classes have been presented at other universities. ${ }^{2-8}$

To facilitate the development of these competencies, a web-based tool is being designed to create a virtual environment in which students can learn about and develop these competencies through the use of self- and peer-assessment in their project teams. ${ }^{9}$ Formative assessments and feedback, which help students identify the next steps to improve their performance and create personalized learning experiences, are a powerful means of enhancing deep learning and meta-cognitive abilities. ${ }^{10}$ In relation to teaching team-effectiveness, students may spend 2-3 hours a week working in a classroom with their instructors on their team-based project but they spend significantly more time working together outside of the classroom. As a result, students may be in a better position to assess and provide personalized feedback on their team members' effectiveness than instructional staff. ${ }^{8}$ However, students require diagnostic instruments with which to assess their team situation along specific behaviours to identify targeted areas for improvement; students often lack the language or experience to identify these areas on their own or may provide a narrow assessment that focuses on only those aspects they feel are important. A Team-effectiveness Inventory (TEI) has been developed to be used in this web-based tool as the basis of the individual behaviour competencies. The objective of this inventory is to guide student reflection by creating a common language by which structured assessments can be provided based on these competencies and converted into personalized feedback.

Teaching of team-effectiveness can occur at either the team or individual level through developing group processes or individual behaviours. ${ }^{11}$ However, at the individual level, while there is a fair consensus about developing skills related to aspects of project management, social and interpersonal relations, collaboration and accountability, there is some divergence in terms of the specific behaviour competencies that should be developed. The focus of this paper is on the development and refinement of the TEI designed to be used by engineering students to facilitate self- and peer-assessments of individual team-member effectiveness. This paper will describe the TEI's initial development, the study in which it was assessed, and the resultant understanding of how students perceived and used the inventory. Finally, improvements made to the inventory will be presented along with future work.

\section{Initial Team-effectiveness Inventory}

The team-effectiveness inventory (TEI) was derived from existing models/inventories on individual team-effectiveness as well as from feedback obtained on common team-dysfunction issues from instructors of team-based project courses at the University of Toronto. A focus in its development was to ensure that it was not solely a measure of team contribution, but an instrument that students could use to reflect past the work-completion component of teamwork to the other non-work-related competencies necessary for success. This inventory was initially presented in Sheridan's framework for teaching team-effectiveness, ${ }^{9}$ and is summarized below.

The TEI categorizes individual competencies into three aspects: Organisational, Relational, and Communication. The Organizational Competencies deal with managing the workflow of the team, the Relational Competencies deal with fostering positive interpersonal relations, and the Communication Competencies deal with the way in which issues and work are presented and discussed. To develop the inventory, a synthesis of other inventories was created and redundancy 
between behaviours eliminated. Some inventories which informed this development include Bushe and Coetzer's ${ }^{5}$ and Maxwell's ${ }^{7}$ inventories which focused heavily on what this inventory terms Relational (conflict management, decision making, cohesion, interdependency) and Organizational (team-member and team performance expectations, direction/goal setting, work processes, etc.) competencies, and Lingard's ${ }^{3}$ which presented some Communication competencies (share opinions and knowledge, listen to others' opinions, consider others suggestions). The resultant list of competencies from this synthesis was then combined with instructor feedback on competencies that they felt should be incorporated or eliminated based on their experience. Utilizing both information sources, the list was refined and simplified based on instructor feedback to create the inventory of 27 individual team-effectiveness competencies shown in Table 1.

Table 1. The 27 competencies of the Team-effectiveness Inventory divided into the three aspects of individual team-effectiveness as presented in Sheridan's framework. ${ }^{9}$

\begin{tabular}{|c|c|c|}
\hline Organisational Aspects & Relational Aspects & Communication Aspects \\
\hline Support team rules & Build the trust of teammates & $\begin{array}{l}\text { Exchange information in a } \\
\text { timely manner }\end{array}$ \\
\hline $\begin{array}{l}\text { Attend team meetings } \\
\text { prepared }\end{array}$ & $\begin{array}{l}\text { Motivate others on the team to } \\
\text { do their best }\end{array}$ & Introduce new ideas \\
\hline $\begin{array}{l}\text { Contribute to making } \\
\text { meetings effective }\end{array}$ & $\begin{array}{l}\text { Raise contentious issues in a } \\
\text { constructive way }\end{array}$ & Openly express opinions \\
\hline Do their fair share of the work & $\begin{array}{l}\text { Solicit input before } \\
\text { proceeding }\end{array}$ & $\begin{array}{l}\text { Promote constructive } \\
\text { brainstorming }\end{array}$ \\
\hline Deliver their work on time & $\begin{array}{l}\text { Adopt suggestions from other } \\
\text { members }\end{array}$ & Actively listen to teammates \\
\hline Produce high quality work & $\begin{array}{c}\text { Accept feedback about } \\
\text { strengths and weaknesses }\end{array}$ & Provide constructive feedback \\
\hline $\begin{array}{l}\text { Help to plan, set goals, and } \\
\text { organize work }\end{array}$ & $\begin{array}{l}\text { Show respect for other } \\
\text { teammates }\end{array}$ & $\begin{array}{l}\text { Make sure that teammates } \\
\text { understand important } \\
\text { information and instructions }\end{array}$ \\
\hline $\begin{array}{l}\text { Track team progress vs. } \\
\text { project timeline }\end{array}$ & Demonstrate accountability & Help the team build consensus \\
\hline $\begin{array}{l}\text { Encourage progress to meet } \\
\text { goals and deadlines }\end{array}$ & Collaborate effectively & \\
\hline $\begin{array}{l}\text { Display dedication and } \\
\text { determination }\end{array}$ & & \\
\hline
\end{tabular}

Students use this inventory as outlined in Sheridan's framework, ${ }^{9}$ as a guide for providing structured assessments on their own and their team-members' effectiveness along each of the 
competencies. When providing an assessment, students use a behaviorally anchored rating system, and rank themselves and their teammates according to a 7-point descriptive Likert scale (similar to a rubric) along each competency that explains the behaviours seen at each level. The model used to develop the descriptions of each competency describes a student's level of engagement in utilizing that competency to improve team performance. The model starts at unengaged (1-3), moves to self-focused (4-5) and finally to team-focused (6-7). To obtain a team-focused rating along each competency the student has to demonstrate an ability to model the behaviours necessary of a competency and promote these behaviours in their team members. As an example, the descriptive assessment scale is presented for three competencies in Table 2. By structuring the assessments, and using descriptions of the different levels of competency, students should: i) all be able to assess according to a common scale, reducing the variation in assessments for a given team member from different teammates, and ii) be able to provide feedback that allows a teammate to easily identify their performance level and how they need to improve.

Table 2. Examples of the descriptive assessment scale for some of the competencies listed in the TEI as presented in Sheridan's framework. ${ }^{9}$

\begin{tabular}{|c|c|c|c|c|c|c|c|}
\hline & 1 & 2 & 3 & 4 & 5 & 6 & 7 \\
\hline Support team rules & $\begin{array}{l}\text { Did not contribute } \\
\text { to the development } \\
\text { or team rules, nor } \\
\text { did they abide by } \\
\text { them during the } \\
\text { project }\end{array}$ & & $\begin{array}{l}\text { Supported only } \\
\text { those rules } \\
\text { which were } \\
\text { convenient or } \\
\text { they felt were } \\
\text { appropriate }\end{array}$ & & $\begin{array}{l}\text { Contributed to } \\
\text { the } \\
\text { development of } \\
\text { the rules and } \\
\text { supported most } \\
\text { of the rules, } \\
\text { most of the } \\
\text { time }\end{array}$ & & $\begin{array}{l}\text { Contributed to } \\
\text { the development } \\
\text { of the rules, and } \\
\text { not only } \\
\text { supported but } \\
\text { assisted other } \\
\text { teammates in } \\
\text { supporting them }\end{array}$ \\
\hline $\begin{array}{l}\text { Motivate others on } \\
\text { the team to do their } \\
\text { best }\end{array}$ & $\begin{array}{l}\text { Did not } \\
\text { demonstrate } \\
\text { interest in the } \\
\text { motivation of } \\
\text { anyone on the } \\
\text { team, including } \\
\text { self }\end{array}$ & & $\begin{array}{l}\text { Did not } \\
\text { demonstrate } \\
\text { interest in the } \\
\text { motivation of } \\
\text { others on the } \\
\text { team }\end{array}$ & & $\begin{array}{l}\text { Attempted to } \\
\text { motivate others } \\
\text { when it was } \\
\text { beneficial to } \\
\text { self, or was not } \\
\text { too time } \\
\text { consuming }\end{array}$ & & $\begin{array}{l}\text { Motivated } \\
\text { others on the } \\
\text { team to do their } \\
\text { best at all times } \\
\text { during the } \\
\text { project }\end{array}$ \\
\hline $\begin{array}{l}\text { Openly express } \\
\text { opinions }\end{array}$ & $\begin{array}{l}\text { Did not express } \\
\text { opinions }\end{array}$ & & $\begin{array}{l}\text { Expressed } \\
\text { opinions in a } \\
\text { manner which } \\
\text { demonstrated } \\
\text { hesitation or } \\
\text { reservation }\end{array}$ & & $\begin{array}{l}\text { Expressed } \\
\text { opinions in an } \\
\text { open manner }\end{array}$ & & $\begin{array}{l}\text { Expressed } \\
\text { opinions in an } \\
\text { open and } \\
\text { unbiased } \\
\text { manner that } \\
\text { solicited input } \\
\text { from others }\end{array}$ \\
\hline
\end{tabular}

Once the team has completed the TEI for all team-members, the assessments are combined and distributed to students as feedback such that they can see their self-assessment and an anonymized list of assessments their team-members provided. The three competencies in which 
the student's performance was the weakest are highlighted in red on the feedback, and the three competencies in which the student's performance was the strongest are highlighted in green to allow students to easily identify their strengths and weaknesses. The feedback is provided to the student along with a copy of the TEI and a list of tools and techniques on how to improve in each competency.

\section{Study Design}

A pilot study to assess the utility of the Team-effectiveness Inventory (TEI) in facilitating useful feedback was tested in the Winter 2012 term of a 250-student cornerstone design course in first year engineering. The objective of the study was to understand how students perceive, interpret and use the inventory so as to revise it to make it more accessible and useful for assessment and feedback.

Before providing assessments, the class attended three half-hour lectures on individual teameffectiveness, and how these behaviours manifest in highly-effective, high performance teams. Following this, in week 7 of a 13 week term, students were asked to provide self- and peerassessments on their effectiveness as team members. Forty-eight percent of the class completed this assessment using the Team-effectiveness Inventory in Table 1, with the remaining 52\% providing free-form feedback. Simultaneously, Teaching Assistants (TAs) in the course completed TEI assessments of all students in their tutorial sections.

One week after completing the assessment, students received their self- and peer- assessments as feedback for review with three strengths and three weaknesses highlighted. At the end of the course (week 13), students in both groups completed the same survey on the usefulness of the feedback they received. Questions in the survey analysed the quantity, depth, and breadth of the feedback as well as its motivation to incite students to improve their individual teameffectiveness. Focus groups with TAs and students who used the inventory were conducted after the second survey to assess the TEI's utility, and capture data on how students perceived and used the TEI.

The rate of students' consent to participate in the research study was high at $77.5 \%$. Thus data was obtained from $100 \%$ of the students but only the data from this $77.5 \%$ was used for the analysis reported in this paper. Since the students had to complete the assessments of their team members for course purposes, as part of a $2 \%$ completed/not-completed deliverable, this high portion of the students were willing to allow their anonymized assessments to be copied over to the research database for this study. However, student participation in the focus groups (either due to the lack of grade-based incentive, or focus group timing - after all exams were completed) was significantly lower than expected making all findings from the focus groups informative, but not statistically significant. All teaching assistants involved in the study participated in a TA focus group.

To guide improvements to the inventory, we sought to understand how students perceived and used the inventory. Using the data gained from the study described above, a mixed methods approach was used to develop this understanding as well as how well the inventory mapped to students' beliefs about team-effectiveness in general. First qualitative information from the focus groups was transcribed and coded to surface common themes from both students and TAs about 
their experiences using the inventory. Following this, findings from the focus groups were then compared to the quantitative data available from student and TA assessments. These data included: i) correlation analyses between competencies, ii) the frequency of a TA not being able to assess a student on a competency, and iii) student feedback on the inventory from the end-ofterm survey (both quantitative and qualitative). From these analyses, general observations of students' perceptions and use of the inventory were obtained, as well as aspect-level interpretations and perceptions of the individual competencies.

\section{How students perceived and used the inventory}

Overall, students perceived the inventory as a useful tool to provide feedback to themselves and their team-members on their individual team-effectiveness as well as to develop a greater understanding of effective team-work. Students found that the feedback was generally phrased in a neutral to positive tone, and that they received enough feedback from the inventory to develop an understanding of themselves and their performance. Of the students who used the inventory, approximately $80 \%$ reported that they felt motivated to improve their performance based on their feedback and over $85 \%$ reported that they spent some time planning or practicing to improve their performance after receiving the feedback. Students did not report any jargon or language in the inventory that was inaccessible.

During the focus group discussion, when students were asked to describe an effective teammember they presented competencies which would have fallen under the organizational or communication aspects of the inventory. Students described operational aspects of team-work with a focus on equitable contribution, commitment, and work initiative. This finding was expected, as the relational component of team-work is the area that was described as the most overlooked by the faculty interviewed in the development of this inventory. One finding that was not expected was that when asked to describe the competencies of an effective team-member, the students described team-members with a learning-orientation - team-members who were fastlearners, were self-directed and were critical thinkers. This demonstrated that students may still be privileging the work-related competencies over the other competencies.

Both students and teaching assistants commented that they would have liked an opportunity to provide textual comments to the recipient of the feedback to explain their assessment. There was much disagreement among the members of the focus groups as to whether the comments should be related to specific competencies or holistic for one team-member's general performance. The students felt that this would be particularly useful as their assessment of each team-member is informed by the student's relative performance compared to all other members of the team, and that by providing such feedback a student could outline the specific behaviours that the teammember did or did not demonstrate in comparison to other members behaviours to justify their assessment.

Teaching assistants who used the inventory commented that it is best-designed for use by teammembers and not by outside observers. Several of the competencies required knowledge of teammechanics that were important to successful team performance but that were not visible to them in the amount of time they spent interacting with the team. This confirmed that the inventory is an internal assessment tool appropriate for self- and peer-assessments. However, students did comment that a debrief for the entire team, facilitated by a teaching assistant, would allow the 
entire team to determine how to be more effective as a whole than they would be able to individually by processing their feedback.

The placement of the inventory in the project cycle was reported by students to be well-timed. Students reported that the mid-term TEI allowed them to gauge their process, reminded them about aspects of teamwork that they otherwise would not have thought about until too late in the project, and as a result, allowed them to readjust their path and fix potential team issues before they became significant. This demonstrated that the students used the competency listing from the inventory both as a guide to reflect on the processes they and their team members were using as well as to provide feedback.

\section{Improvements made to the Team-effectiveness Inventory}

Four types of modifications were made to the inventory: removal of competencies, combining competencies, relocating competencies between the aspects, and rephrasing competencies. These modifications were informed by the analysis discussed in the previous section as well as two requests from the instructional staff of the design courses at the University: i) to create an instrument that allowed students to assess their entire team in less than half an hour, and ii) to allow the instructional staff to obtain information about student work contribution. As a result, modifications which reduced the total number of competencies, and those which created the greatest amount of differentiation amongst the behaviours being assessed were privileged.

A Spearman's rank correlation was first completed to determine competencies which should be flagged for further investigation using qualitative data. Overall, all 27 competencies were highly correlated with each other; no two competencies had a correlation of less than 0.5. Such high correlation values were expected as the competencies combine to create an effective teammember, and thus someone who is a highly-effective team member would be expected to have high competence across all of the behaviours. As a result, the critical limit of 0.1 was not informative in completing this flagging and a cut-off of 0.75 was decided on as it identified an appropriate number of competencies to be investigated to reduce the inventory. All competency correlations which fell above this cut-off value are presented below in Table 3.

Table 3. Competency correlations which had a Spearman's rho $(\rho)$ of greater than 0.75 and were identified as candidates for potential modification.

\begin{tabular}{llc}
\hline COMPETENCY & COMPETENCY & p \\
\hline Do their fair share of the work & Deliver their work on time & 0.83 \\
\hline Track team progress vs. project timeline & $\begin{array}{l}\text { Encourage progress to meet goals and } \\
\text { deadlines }\end{array}$ & 0.80 \\
\hline $\begin{array}{l}\text { Help to plan, set goals, and organize } \\
\text { work }\end{array}$ & $\begin{array}{l}\text { Encourage progress to meet goals and } \\
\text { deadlines }\end{array}$ & 0.76 \\
\hline $\begin{array}{l}\text { Encourage progress to meet goals and } \\
\text { deadlines }\end{array}$ & Display dedication and determination & 0.76 \\
\hline $\begin{array}{l}\text { Help to plan, set goals, and organize } \\
\text { work }\end{array}$ & Track team progress vs. project timeline & 0.76 \\
\hline Support team rules & $\begin{array}{l}\text { Encourage progress to meet goals and } \\
\text { deadlines }\end{array}$ & 0.76 \\
\hline
\end{tabular}




\begin{tabular}{llc}
\hline Do their fair share of the work & Produce high quality work & 0.75 \\
\hline contribute to making meetings effective & Help to plan, set goals, and organize work & 0.75 \\
\hline Display dedication and determination & Motivate others on the team to do their best & 0.75 \\
\hline Adopt suggestions from other members & $\begin{array}{l}\text { Accept feedback about strengths and } \\
\text { weaknesses }\end{array}$ & 0.76 \\
\hline Demonstrate accountability & Collaborate effectively & 0.75 \\
\hline Show respect for other team members & Collaborate effectively & 0.75 \\
\hline Collaborate effectively & Help the team build consensus & 0.78 \\
\hline Promote constructive brainstorming & Provide constructive feedback & 0.80 \\
\hline $\begin{array}{l}\text { Make sure that team members } \\
\text { understand important information \& }\end{array}$ & Help team build consensus & 0.77 \\
\hline Opentructions express opinions & Promote constructive brainstorming & 0.76 \\
\hline Provide constructive feedback & $\begin{array}{l}\text { Make sure that team members understand } \\
\text { important information \& instructions }\end{array}$ & 0.76 \\
\hline Actively listen to team members & Provide constructive feedback & 0.75 \\
\hline
\end{tabular}

\subsection{Removal of competencies}

Competencies whose intended meanings were encompassed by other competencies, and those which the students and teaching assistants found difficult to understand or had multiple interpretations of were considered for removal.

Within the organizational aspect, three competencies were removed: support team rules, contribute to making meetings effective, and display dedication and determination. The support team rules competency was removed as some courses do not have students document a set of rules or norms of behaviour and as a result this question was not relevant to all students. This made assessments along this competency unreliable. The contribute to making meetings effective competency was removed as the term effective was interpreted in many ways by the students making the competency too vague. Instead of rephrasing, this competency was removed as it was seen to be included partially in the attend team meetings prepared competency and the competency promote productive discussion that will be discussed in the combined competencies section. The display dedication and determination competency was removed as the focus group data demonstrated that it was a difficult competency to assess due to interpretation and its assessments were highly correlated with those of motivate others on the team to do their best, and encourage progress to meet goals and deadlines. Since the essence of this competency was already encompassed in other competencies it was deemed redundant and eliminated

Within the relational aspect, two competencies were removed: accept feedback about strengths and weaknesses and collaborate effectively. The accept feedback competency was removed as feedback is a form of suggestion for improvement, and this competency was seen as the selfefficacy component that is a precursor to the competency adopt suggestions from other members. Additionally, the two competencies were highly correlated and students often referenced the two competencies together. The collaborate effectively competency was removed as it was highly 
correlated to three other competencies and was not a well-defined, observable behaviour in its own right.

Within the communication aspect only one competency was removed: make sure that team members understand important information and instructions. This competency was a point of contention in the focus groups as to whether this type of behaviour would result in a dominant person taking control of the group or if it was a more specific version of the exchange information in a timely manner competency. Due to its similarity to the exchanging information competency and its high correlation with the competencies that formed the promote productive discussion competency, it was removed.

\subsection{Combination of competencies}

Competencies whose intended meanings were seen as very similar, and which students and teaching assistants often discussed together were considered for combining into one competency. This allowed the number of competencies to be reduced without the removal of meaning from the inventory.

Within the organizational aspect the two competencies help to plan, set goals, and organize work and track team progress vs. project timeline were combined as both addressed aspects of setting up and monitoring the progress of the workflow in the team. Both of the competencies were highly correlated to each other as well as the competency encourage progress to meet goals and deadlines. As the monitoring component of the competencies was seen to be encompassed in the encouragement competency, it was felt that the two competencies should be combined to reflect establishing and organizing the work for the team. The wording help to plan and organize workflow was chosen as it eliminated the goals component covered in the encouragement competency, and by using the term workflow instead of work, the competency aims to demonstrate a sense of timeline and progression instead of work completion.

Within the communication aspect, the competencies introduce new ideas and openly express opinions were merged as students often referred to the open discussion of ideas and opinions together. Teaching assistants expressed concerns that the introduce new ideas competency privileged extraverts in particular due to the nature of conceptual design work, but did not express concern over expressing opinions. As a result these competencies were combined to create an openly express ideas and opinions competency.

\subsection{Relocation of competencies between aspects}

Competencies whose intended meanings did not map to the meaning of the aspect as expected were relocated to a more appropriate area of the inventory. Competencies were moved between the relational and communication aspects based on focus group findings and the correlation analysis as it emerged that students did not perceive their relevance to the aspect in the way that the inventory designers did.

Two competencies were relocated from the relational to communication aspect: raise contentious issues in a constructive way, and solicit input before proceeding. While both of these competencies have relational and communication aspects, the designers believed that both competencies required high trust, and emotional intelligence to facilitate the types of discussions 
addressed by these competencies. However, the assessments along these competencies were more highly correlated with those of the communication aspect, and when these competencies were discussed by the students and teaching assistants, they were discussed as though they were communication-related competencies. As a result, they were moved to the communication aspect.

One competency was moved from the communication aspect to the relational aspect: help the team build consensus. Given the discussion of different perspectives and negotiation to build consensus, this competency was perceived by the designers to be primarily communication focused. However, based on the correlation analysis and from student discussions in the focus groups it became clear that this competency was perceived to be more related to the relational aspect competencies. This was due to the fact that consensus building requires the ability to understand your and your team members' perspectives as well as the collective good of the team. As a result, given the competencies relational merits, it was moved to the relational aspect.

\subsection{Rephrasing of competencies}

Rephrasing of competencies was considered for competencies which had similar wording and where student assessments between these competencies were highly correlated. Two common words demonstrated high correlations in assessment: effective and constructive. As all competencies with the term effective have already been eliminated, only those with the term constructive were considered herein. These competencies were: raise contentious issues in a constructive way, provide constructive feedback, and promote constructive brainstorming. While these three competencies all deal with presenting information in a manner that will facilitate greater openness and productivity amongst the team members, it was unclear whether the correlation could be attributed to the common phrasing or to the actual competencies themselves. As a result, the competency on contentious issues was left with the term constructive, as that competency required an essence of building a better functioning team that no other word could provide. The providing feedback and promoting brainstorming competencies demonstrated an open sharing of ideas in a manner that would increase team productivity that did not touch require the same caution as raising contentious issues. Additionally, both providing feedback and promoting brainstorming were seen to be highly linked, both in correlation analyses and in the language students used in the focus groups to describe the types of discussions that were helpful to making progress. Feedback was seen as increasing the productivity of the team members, where brainstorming was seen as increasing the productivity of the design work. As a result, both competencies were decided to be merged into a new competency promote productive discussion that did not have the term constructive and encompassed the types of conversations previously outlined by the two competencies.

\subsection{Improved Team-effectiveness Inventory}

Based on the changes discussed above, the revised team-effectiveness inventory developed from this study is presented in Table 4. As can be seen in the revised inventory there is now an equal number of competencies in each aspect such that no aspect can be perceived to be more important. The organizational aspect continues to have a high work focus so that instructional staff can deduce team-contribution information in a manner that is not explicit to students. The 
total number of competencies was also reduced by $1 / 3$ to reduce average completion time from 45 to 30 minutes.

Table 4. The 18 competencies of the Team-effectiveness Inventory divided equally into the three aspects of team-effectiveness.

\begin{tabular}{ccc}
\hline Organisational Aspect & Relational Aspect & Communication Aspect \\
\hline $\begin{array}{c}\text { Encourage progress to meet } \\
\text { goals and deadlines } \\
\text { Attend team meetings } \\
\text { prepared }\end{array}$ & $\begin{array}{c}\text { Build the trust of teammates } \\
\text { Motivate others on the team to } \\
\text { do their best }\end{array}$ & $\begin{array}{c}\text { Exchange information in a } \\
\text { timely manner } \\
\text { Openly express ideas and } \\
\text { opinions }\end{array}$ \\
$\begin{array}{c}\text { Do their fair share of the work } \\
\text { Deliver their work on time }\end{array}$ & $\begin{array}{c}\text { Help the team build consensus } \\
\text { Adopt suggestions from other } \\
\text { members }\end{array}$ & $\begin{array}{c}\text { Promote productive discussion } \\
\text { Produce high quality work }\end{array}$ \\
$\begin{array}{c}\text { Show respect for other } \\
\text { teammates }\end{array}$ & $\begin{array}{c}\text { Solicit input before } \\
\text { proceeding }\end{array}$ \\
Help to plan and organize & Demonstrate accountability \\
workflow & $\begin{array}{c}\text { Raise contentious issues in a } \\
\text { constructive way }\end{array}$ \\
\hline
\end{tabular}

\section{Conclusions and Future Work}

This paper presents the results of a study to assess and improve the utility of a team-effectiveness inventory used to guide reflection and provide feedback to students on their individual teameffectiveness competencies in team-based project courses. The inventory presented is designed to be used in conjunction with the online tool presented in Sheridan's framework ${ }^{9}$ for students to develop these competencies in a manner which is integrated with their technical course material. Based on student feedback from surveys and a focus group, the students found that the feedback received from the inventory motivated them to improve and reminded them of all the aspects of team-work at the midpoint of the course which allowed them to improve their performance. The inventory was then reduced from an initial 27 competencies to 18 competencies based on the results of this study such that competency behaviours were more distinct and so that inventory completion time would be reduced.

The improved inventory has been tested in two upper-year courses at the University of Toronto in Fall 2012 in a leadership-focused and an energy-policy focused course to obtain preliminary information about how students are using the new inventory. In Winter 2013, the inventory will be tested again in two cornerstone design courses (1000 and 300 students each) to assess its ability to guide first-year students in developing their individual team-effectiveness and statistically validate the inventory. It is expected that through this intentional teaching of team effectiveness that there will be an increase in student performance in team-based projects due to a greater ability to understand and address team dynamics. 


\section{Acknowledgments}

Funding for this research was provided by the Higher Education Quality Council of Ontario, the Dorothy and William Palm Queen Elizabeth II Graduate Scholarship in Science and Technology, and the University of Toronto Open Fellowship Fund. The opinions, findings, conclusions and recommendations expressed are those of the authors and do not necessarily reflect the views of the Higher Education Quality Council of Ontario.

\section{References}

1 J. D. Bronzino, D.J. Ahlgren, C-L. Chung, J. D. Mertens, and J. L. Palladino. "Design and Teamwork: A Must for Freshmen." IEEE Transactions on Education, vol. 37, no. 2, pp. 184-188, 1994.

2 L. Morell de Ramirez, J. I. Velez-Arocho, J. L. Zayas-Castro and M. A. Torres, "Developing and Assessing Teamwork Skills in a Multi-disciplinary Course," in Frontiers in Education Conference, Tempe, AZ, 1998.

3 R. W. Lingard, "Teaching and Assessing Teamwork Skills in Engineering and Computer Science," Journal of Systemics, Cybernetics and Informatics, vol. 8, no. 1, pp. 34-37, 2010.

4 B. M. Barkel, "Teaching Team and Interpersonal Skills via Design Projects Transplanting an Industrial Team Model," in International Conference on Engineering Education, Gainsville, FL, 2004.

5 G. R. Bushe and G. Coetzer, "Appreciative Inquiry as a Team-Development Intervention: A Controlled Experiment," Journal of Applied Behavioral Science, vol. 31, no. 1, pp. 13-30, 1995.

6 T. J. Moore, H. Diefes-Dux and P. K. Imbrie, "Assessment of Team Effectiveness During Complex Mathematical Modeling Tasks," in 36th ASEE/IEEE Frontiers in Education Conference, San Diego, CA, 2006.

7 J. Maxwell, July 2011. [Online]. Available: http://www.firststepstraining.com/resources/teq/index.htm.

8 J. McGourty, "Using Multisource Feedback in the Classroom: A Computer-Based Approach," IEEE Transactions on Education, vol. 43, no. 2, pp. 120-124, 2000.

$9 \quad$ P. K. Sheridan, G. Evans, and D. Reeve, “A Proposed Framework for Teaching Team-effectiveness in Teambased Projects,” American Society of Engineering Education Annual Conference and Exposition, San Antonio, Texas, 2012. 11 pages.

10 W. J. Popham, Transformative Assessment, ASCD, 2008.

11 M. I. D. Pina, A. M. R. Martinez, and L. G. Martinez "Teams in organizations: a review on team effectiveness." Team Performance Management, vol. 14, no. 1/2, pp. 7-21, 2008. 